\title{
Fertigação em mudas de citros utilizando-se mangueiras e microtubos sob regime de escoamento turbulento ${ }^{1}$
}

\author{
Wanderley J. Souza ${ }^{2}$, Tarlei A. Botrel ${ }^{2}$, D aniel F. de Carvalho ${ }^{3} \&$ Leonardo D. B. da Silva ${ }^{3}$
}

\begin{abstract}
RESUMO
A irrigação localizada utilizando-se microtubo como emissor operando em regime de escoamento turbulento, pode ser uma alternativa viável, tanto técnica como economicamente para a produção de mudas de citros. O bjetivou-se, com este trabal ho, avaliar o desempenho de um sistema de fertigação na produção de mudas de laranja em viveiro projetado pelo modelo matemático universal, utilizando-se microtubos como emissores, sob regime de escoamento turbulento e comparar o desenvolvimento das plantas fertigadas por microtubos com o sistema em que se utiliza o método tradicional com mangueiras. No dimensionamento do comprimento dos emissores considerou-se o coeficiente $\mathrm{K}$ de dissipação de energia localizada através de um microtubo com diâmetro interno de $0,761 \mathrm{~mm}$. 0 sistema de fertigação apresentou bom desempenho, com valores de grau de entupimento, uniformidade de Christiansen e uniformidade de emissão iguais a 0,50; 99,95 e 98,21\%, respectivamente, após 160 dias de estudo. As plantas cultivadas via fertigação com microtubos e mangueiras, não apresentaram diferenças no que se refere ao diâmetro do caule e à altura. Desta forma, o uso de microtubo sob escoamento turbulento apresentou viabilidade técnica para fertigação.
\end{abstract}

Palavras-chave: emissor, entupimento, irrigação localizada, irrigação de precisão

\section{Fertigation on citrus seedlings using hoses and microtubes under turbulent flow regime}

\begin{abstract}
The use of localized irrigation using microtube as emitter under turbulent flow regime can be a technically feasible alternative. The objective of this study was to evaluate the performance of a fertigation system in nursery of citrus plants (greenhouse) projected by universal mathematical model, using the microtubes as emitters, under turbulent flow rate and to compare the development of the fertigated plants by microtubes to the system that use the traditional method with hoses. In the size of the length of the emitters was considered the $\mathrm{K}$ coefficient of local ized energy dissipation using a microtube with internal diameter of $0,761 \mathrm{~mm}$. The fertigation system presented great performance with clogging degree, Christiansen uniformity and emission uniformity values equal to 0,$50 ; 99,95$ and $98,21 \%$, respectively, after 160 days of study. Plants that were grown using fertigation with both microtubes and hoses showed no difference as regards to stem diameter and height. Thus, the use of the microtube under turbulent flow rate presented technical feasible for fertigation system.
\end{abstract}

Key words: emitter, clogging, localized irrigation, precision irrigation

\footnotetext{
${ }^{1}$ Parte da Dissertação de mestrado do primeiro autor apresentada ao curso de Pós-graduação em Irrigação \& Drenagem, ESALQ/U SP; Projeto financiado pela FAPESP

${ }^{2}$ ESALQ /U SP,Av. Pádua Dias 11, CP 09, CEP 13418-900, Piracicaba,SP. Fone: (19)3447-8549. E-mail: wjsouza@esalq.usp.br;tabotrel@esal q.usp.br 3 IT/U FRRJ, BR465, km 7. Seropédica, RJ. Fone: (21) 26821864. E-mail: carvalho@ufrrj.br;irriga@ufrrj.br
} 


\section{INTRODUÇÃO}

A fertigação é uma técnica bastante explorada na área agrícola e que tem, como objetivo, reduzir os custos com mãode-obra resultantes da aplicação de fertilizante e suprir água e nutrientes à cultura, podendo ser aplicado fertilizante líquido solúvel (Laurindo et, al., 2010). Uma vez que o nutriente é fornecido juntamente com a água (essencial para sua absorção), esta técnica apresenta outras vantagens, entre as quais a melhor distribuição do fertilizante e a possibilidade de maior parcelamento das adubações, aumentando a absorção de nutrientes pelas plantas (Duenhas et al., 2005). Apesar do grande potencial para utilização o número de pesquisas que tratam da aplicação de nutrientes via fertigação em mudas de citros, ainda é pequeno (Vale et al., 2009).

Para ser eficiente a fertigação deve ser realizada com os nutrientes na profundidade de máxima densidade de raízes; por outro lado, quando a lâmina de irrigação é insuficiente os nutrientes podem se concentrar próximos à superfície do solo; logicamente, as raízes crescem menos e exploram menor volume de solo, condições em que pode ocorrer acúmulo de sais, elevação da pressão osmótica da solução do solo e redução na produtividade das culturas (Donagemma et al., 2009).

Quando se trabalha com citricultura alguns produtores de mudas de laranja realizam a irrigação das plantas utilizando mangueiras de polietileno através das quais a água é aplicada para suprir as necessidades hídricas das plantas; entretanto, esta técnica apresenta dois fatores importantes a serem analisados, ou seja, grande quantidade de mão-de-obra e desperdício ou a insuficiência na aplicação de água (Souza, 2008). O uso de mangueiras requer pessoal treinado para distribuição da água, planta por planta, em todo o viveiro, uma vez que a aplicação excessiva conduz ao desperdício de água e aumento na lixiviação de nutrientes quando se trabalha com fertigação, acarretando prejuízos para a empresa produtora de mudas de laranja (Souza, 2008). Além disso, os excessos dos íons sódio e cloretos deixados no substrato pela fertigação passam a ser assimilados em altas concentrações pelos tecidos das plantas, podendo ocorrer estresse mineral por toxidez, o que dificulta a absorção de íons essenciais, acarretando estresse mineral por deficiência nutricional (Soares et al., 2005). Por outro lado, se o tempo de aplicação da água for inferior àquele determinado em fase de projeto, o déficit na quantidade de água aplicada poderá causar estresse pela desidratação além de efeito osmótico considerável (Soares, 2007). O estresse salino induz ao menor consumo de água e, como consequência, menor crescimento das plantas (Dias et al., 2005).

Uma alternativa ao método tradicional com mangueiras para aplicação de água em mudas de citros cultivadas em viveiro, é o uso da irrigação localizada, com a qual é possível aplicar a lâmina requerida de maneira mais precisa, reduzindo a quantidade de mão-de-obra, o desperdício de água (Bhatnagar\& Srivastava, 2003) e, em consequência, nutrientes, quando se trabalha com fertigação. Na irrigação localizada uma maneira prática e de baixo custo para irrigar com o mínimo de desperdício é aplicar água via microtubo. Este emissor, também chamado "tubo spaghetti", apresenta facilidade na instalação e é constituído de polietileno liso, com diâmetros que variam de 0.5 a $1.5 \mathrm{~mm}$. Por ser este um emissor de longo percurso, a dissipação de energia pela passagem da água dentro dele permite, por meio de ajuste do comprimento, obter-se uma vazão uniforme dos emissores inseridos ao longo de uma linha lateral. Para sua utilização existem alguns fatores relevantes que devem ser considerados: a fração da energia cinética (coeficiente K) devido à passagem do líquido de uma zona de maior área transversal para dentro do microtubo; a dissipação de energia em virtude da velocidade de saída do líquido (Ev) e a dissipação de energia dentro do microtubo (HfTubo) (Souza et al., 2004). De acordo com Souza (2008), para maior precisão e facilidade nos cálculos esses fatores podem ser determinados, testados em laboratório e inseridos em um modelo matemático para dimensionamento dos microtubos.

Em regime de escoamento laminar tendo em vista a baixa velocidade da água, os microtubos são sensíveis a entupimentos, conforme verificado por Souza et al. (2004), mesmo com a presença de sistema de filtragem, o que se torna um entrave, haja vista que, mesmo com uma pequena porcentagem de emissores obstruídos, é possível obter grande redução na uniformidade de aplicação da lâmina de irrigação, interferindo no desenvolvimento das plantas (Souza et al., 2006). Por outro lado, em regime turbulento este problema pode ser minimizado permitindo bom desempenho do sistema e suprimento adequado das necessidades hídricas das culturas (Souza, 2008). Apesar disto, o uso de fertilizantes solúveis e uma boa filtragem não são dispensados, principalmente em função de partículas físicas que a água pode conter.

A pesquisa descrita neste trabalho enfocou a investigação de um método alternativo de fertigação com microtubos operando em regime de escoamento turbulento, comparado ao sistema tradicional com mangueiras. O sistema de fertigação foi avaliado em função das vazões apresentadas, do grau de entupimento dos emissores e pelo desenvolvimento das plantas cultivadas em bancada experimental comparadas com as plantas manejadas utilizando-se o método tradicional de irrigação com mangueiras.

\section{MATERIAL E MÉTODOS}

O experimento foi conduzido na Fazenda Candelária, no município de Araras, SP, na qual foi implantado um sistema de fertigação em mudas de laranja sob ambiente protegido, em parceria com o Departamento de Engenharia de Biossistemas da ESALQ/USP. Os emissores utilizados para irrigação foram microbutos com diâmetro interno de $0,761 \mathrm{~mm}$ e externo de 2,50 $\mathrm{mm}$, com comprimentos diferenciados instalados na bancada experimental, ao longo da linha lateral, a fim de uniformizar a vazão em cada planta.

Para dimensionar os comprimentos dos microtubos de forma precisa, utilizou-se o modelo matemático-hidráulico Universal (Eq.1), proposto por Souza (2008), fundamentado na Figura 1, apresentada a seguir. O modelo foi desenvolvido através da metodologia de dimensionamento passo a passo, considerando-se a equação de Darci-Weistbach para determinação das energias dissipadas no cabo e no microtubo, 
e as equações de dissipação de energia localizada, em função da inserção do emissor e da velocidade da água, na saída do microtubo.

$$
\mathrm{L}_{\mathrm{B}-\mathrm{C}}=\left\{\begin{array}{c}
{\left[\begin{array}{c}
\left.\mathrm{P}_{\mathrm{D}}-\mathrm{Hf}_{\mathrm{L}} \pm \mathrm{dZ}-\left(\mathrm{Z}_{\mathrm{C}}-\mathrm{Z}_{\mathrm{A}}\right)+\left(\frac{\mathrm{V}_{\mathrm{D}}{ }^{2}}{2 \mathrm{~g}}-\frac{\mathrm{V}_{\mathrm{A}}{ }^{2}}{2 \mathrm{~g}}\right)\right]- \\
{\left[\frac{0,316}{2 \mathrm{~g}}\left(\frac{4}{\pi}\right)^{1,75} \frac{\left.\mathrm{v}_{0,25}\left(\frac{\mathrm{q}^{1,75} \mathrm{~L}_{\mathrm{A}-\mathrm{B}}}{1}\right)\right]-}{\left.\left.\mathrm{d}_{\mathrm{A}}^{1,75}\right)\right]}\right.} \\
{\left[\frac{16}{2 \pi^{2} \mathrm{~g}}\left(\frac{\mathrm{q}^{2}}{\mathrm{~d}_{\mathrm{B}}{ }^{4}}\right)\right]-\left[\frac{16}{2 \pi^{2} \mathrm{~g}}\left(\mathrm{~K} \frac{\mathrm{q}^{2}}{\mathrm{~d}_{\mathrm{B}}{ }^{4}}\right)\right]}
\end{array}\right\}\left[\frac{1,310500 \mathrm{gd}_{\mathrm{B}}^{4,75}}{0,31 v^{0,25}} \frac{\mathrm{q}^{1,75}}{}\right]}
\end{array}\right.
$$

em que:

$\mathrm{P}_{\mathrm{D}}$ - carga de pressão na entrada do cabo, no penúltimo microtubo, m.c.a. $\mathrm{A}, \mathrm{m}$

$\mathrm{Hf}_{\mathrm{L}}$ - energia dissipada na linha lateral, entre os pontos D e

$\mathrm{dZ}$ - diferença de nível entre D e A, $\mathrm{m}$

$\mathrm{Z}_{\mathrm{C}}$ e $\mathrm{Z}_{\mathrm{A}}$ - cotas nos pontos $\mathrm{C}$ e $\mathrm{A}$, respectivamente, $\mathrm{m}$

q - vazão que se deseja no microtubo, $\mathrm{m}^{3} \mathrm{~s}^{-1}$

$v$ - viscosidade cinemática, $\mathrm{m}^{2} \mathrm{~s}^{-1}$

$\mathrm{d}_{\mathrm{A}}$ e $\mathrm{d}_{\mathrm{B}}$ - os diâmetros internos do cabo e do microtubo, respectivamente, $\mathrm{m}$

$\mathrm{L}_{\mathrm{A}-\mathrm{B}}$ e $\mathrm{L}_{\mathrm{B}-\mathrm{C}}$ - comprimentos do cabo e do microtubo, respectivamente, $\mathrm{m}$

$\mathrm{K}$ - constante de dissipação de energia na entrada do microtubo

$\mathrm{V}_{\mathrm{A}} \mathrm{eV}_{\mathrm{D}}$ - velocidades da água nos pontos $\mathrm{Ae} \mathrm{D}$, respectivamente, na linha lateral, $\mathrm{m} \mathrm{s}^{-1}$

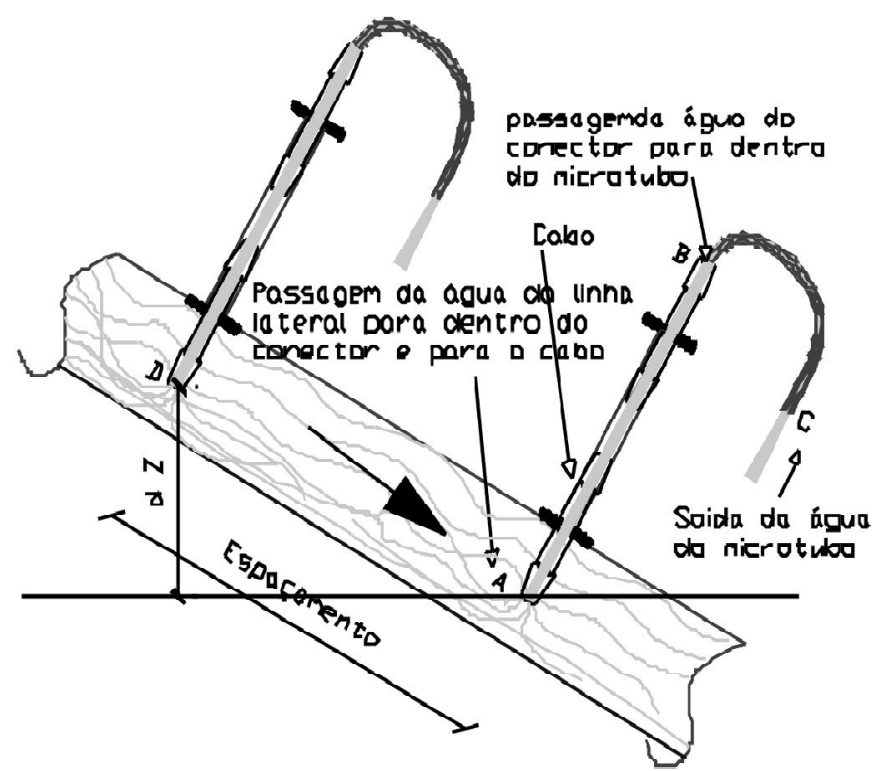

Figura 1. Ilustração do fluxo da água no sistema com microtubos, pelo dimensionamento passo a passo, do ponto D (microtubo anterior) até a saída em C

As velocidades $\mathrm{V}_{\mathrm{A}}$ e $\mathrm{V}_{\mathrm{D}}$ serviram como dados de entrada no modelo, sendo estimadas em função da vazão que escoa na tubulação lateral, dada por:

$$
\mathrm{V}=4 \mathrm{Q}\left(\pi \varnothing^{2}\right)^{-1}
$$

em que:

Q - vazão $\left(\mathrm{m}^{3} \mathrm{~s}^{-1}\right)$ nas seções A e D, obtida pela diferença entre a vazão total na linha lateral menos a vazão dos microtubos anteriores, considerando-se o dimensionamento realizado do final para o início da linha lateral

$\varnothing$ - diâmetro da linha lateral, $\mathrm{m}$

$\pi$ - constante com valor aproximado em 3, 141592654

No campo, a função do cabo é fazer a ligação entre a linha lateral e o microtubo, possibilitando redução no comprimento do microtubo e, consequentemente, na pressão no início da linha lateral. Quando não for necessária a utilização do cabo, como é o caso desta pesquisa, as variáveis da equação a ele relacionadas, são consideradas nulas.

Os valores da constante $\mathrm{K}$ de dissipação de energia na entrada do microtubo foram determinados por Souza (2008) através da equação universal, para calcular a perda de carga no microtubo, a equação que determina as perdas de carga por energia de velocidade na saída do microtubo e localizada, isolando-se o coeficiente $\mathrm{K}$. Para tanto, o autor utilizou diferentes comprimentos de microtubos $(0,10 ; 0,15 ; 0,20 ; 0,25 \mathrm{e}$ $0,30 \mathrm{~m})$, submetidos a 16 diferentes pressões, variando de 40 a $420 \mathrm{KPa}$, obtendo então diferentes vazões, valores de $\mathrm{K}$ e número de Reynolds; em seguida, ajustou-se uma equação que relaciona os valores de $\mathrm{K}$ obtidos com os diferentes comprimentos de microtubo, em função do número de Reynolds (R) conforme Eq. 3.

$$
\mathrm{K}=2832 \mathrm{R}^{-0,8067}
$$

O número de Reynolds ( $R$ ) é função da vazão $\left(\mathrm{m}^{3} \mathrm{~s}^{-1}\right)$ no microtubo $(\mathrm{q})$, diâmetro $\left(\mathrm{d}_{\mathrm{B}}\right)$ do microtubo $(\mathrm{m})$ e viscosidade cinemática $(v)$ da água $\left(\mathrm{m}^{2} \mathrm{~s}^{-1}\right)$ conforme a Eq.4. A viscosidade cinemática foi determinada em função da temperatura da água utilizada no teste, que variou de 295 a $302 \mathrm{~K}$

$$
\mathrm{R}=4 \mathrm{q}\left(\pi \mathrm{d}_{\mathrm{B}} v\right)^{-1}
$$

Os valores de K em função de Reynolds obtidos por Souza (2008) e as vazões correspondentes, estão na Tabela 1, determinados para o microtubo utilizado.

Para implantação do sistema de fertigação foram utilizadas 560 mudas de laranja com sete fileiras sobre uma bancada experimental. A metade das plantas foi fertigada manualmente

\begin{tabular}{|c|c|c|}
\hline Valores de K & $\begin{array}{c}\text { Reynolds } \\
\text { (adimensional) }\end{array}$ & $\begin{array}{l}\text { Vazão } \\
\left.\left(L^{-1}\right)^{\prime}\right)\end{array}$ \\
\hline 3,52 & 4000 & 7,22 \\
\hline 3,20 & 4500 & 8,07 \\
\hline 3,03 & 4810 & 8,60 \\
\hline 2,94 & 5000 & 8,92 \\
\hline 2,72 & 5500 & 9,77 \\
\hline 2,54 & 6000 & 10,62 \\
\hline 2,38 & 6500 & 11,47 \\
\hline 2,24 & 7000 & 12,32 \\
\hline
\end{tabular}
utilizando-se mangueiras de polietileno, conforme os

Tabela 1. Coeficientes $K$ de dissipação de energia para diferentes valores de Reynolds e vazão de projeto 
procedimentos da empresa; nas outras 280 mudas de laranja instalaram-se quatro linhas laterais sobre a bancada, conforme a Figura 2, sendo três alimentando 80 microtubos e a outra alimentando 40; na saída de cada emissor foram colocadas mangueiras de $20 \mathrm{~mm}$ de diâmetro, perfuradas e cortadas em comprimentos de $20 \mathrm{~mm}$, com o objetivo de reduzir o alcance do jato emitido pelo microtubo.

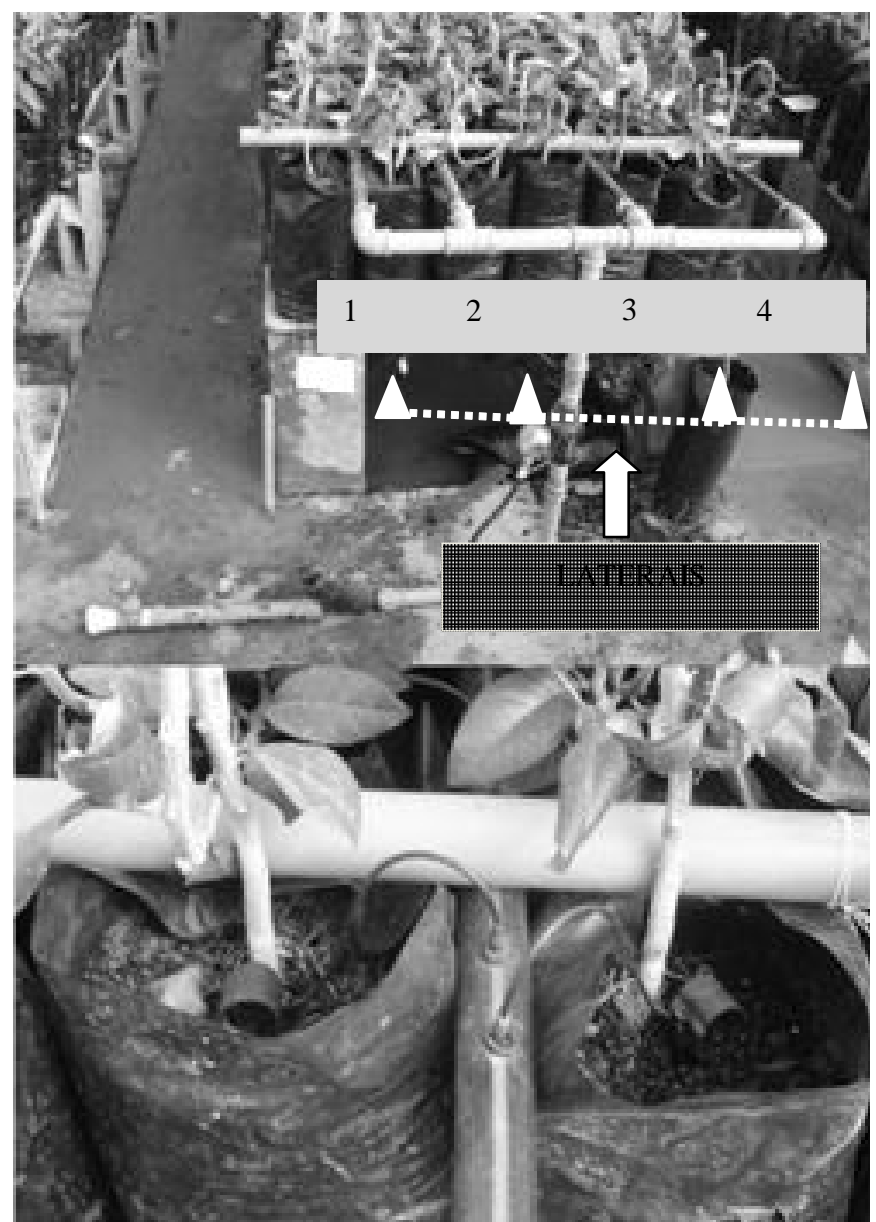

Figura 2. Sistema de fertigação com microtubos instalados na bancada complantas

O dimensionamento dos comprimentos dos microtubos nesta pesquisa foi realizado utilizando-se coeficiente $\mathrm{K}$ igual a 3,03 e vazão de $8,60 \mathrm{~L} \mathrm{~h}^{-1}$ com Reynolds, aproximadamente 4810 (regime de escoamento turbulento). A pressão no inicio da linha lateral foi de $200 \mathrm{kPa}$ e os comprimentos dos microtubos determinados pela Eq. 1 variaram de 0,18 a $0,20 \mathrm{~m}$, ao longo de cada lateral, situando-se entre os valores utilizados quando se determinou o coeficiente K. O manejo do sistema de irrigação com os microtubos foi realizado utilizando-se turnos de rega, de três e quatro dias, com tempos de aplicação da água de 180 e $240 \mathrm{~s}$, respectivamente.

Os produtos utilizados na quimigação foram: ácido fosfórico e ácido bórico; nitrato de amônio, nitrato de cálcio e nitrato de potássio; sulfato de potássio, sulfato de magnésio, sulfato de zinco, sulfato de cobre e sulfato de ferro e molibidato de amônio. As concentrações dos produtos na água de irrigação estão apresentadas na Tabela 2, em dois coquetéis, um para cada época, em função das necessidades nutricionais das mudas de laranja. A solução na saída do microtubo foi produzida em função da diluição dos coquetéis em 24 vezes, obtendo-se uma condutividade elétrica de 2,00 a 2,50 dS m $\mathrm{d}^{-1}$.

Tabela 2. Concentração dos minerais utilizados na fertirrigação das mudas de laranja

\begin{tabular}{cc}
\hline $\begin{array}{c}\text { Coquetel A para } 1000 \\
\text { litros de água }\end{array}$ & $\begin{array}{c}\text { Coquetel B para } 1000 \\
\text { litros de água }\end{array}$ \\
& Nitrato de cálcio $(0,015 \mathrm{Mg})$ \\
& Nitrato de potássio $(0,010 \mathrm{Mg})$ \\
& Sulfato ferroso $(25,00 \%)(0,03 \mathrm{Mg})$ \\
Ácido fosfórico $(3,00 \mathrm{~L})$ & Ferro quelatizado $(6,00 \%)$ \\
Nitrato de potássio $(0,015 \mathrm{Mg})$ & Sulfato de zinco $0,0015 \mathrm{Mg})$ \\
Sulfato de magnésio $(0,018 \mathrm{Mg})$ & Sulfato de manganês $(0,001 \mathrm{Mg})$ \\
& Sulfato de cobre $(0,0012 \mathrm{Mg})$ \\
& Ácido bórico $(0,000005 \mathrm{Mg})$ \\
& Molibidato de sódio $(0,000001 \mathrm{Mg})$ \\
\hline
\end{tabular}

A vazão nos emissores foi avaliada durante dois períodos: 60 e 160 dias após implantação. Para verificação do desempenho hidráulico as vazões foram determinadas pesando-se o volume de água coletado em um tempo não inferior a três minutos. As amostras foram utilizadas para quantificação do índice de erro da vazão; erro médio absoluto da vazão; coeficiente de variação de vazão, que segue a mesma metodologia do coeficiente de variação de fabricação, conforme Solomon (1979); coeficiente de uniformidade de Christiansen; uniformidade de emissão da água e o grau de entupimento dos emissores, empregando-se as Eqs. de 5 a 10.

$$
\begin{gathered}
\text { Is }=\left(\frac{\sum_{\mathrm{i}=1}^{\mathrm{N}}(|\mathrm{Ei}-\mathrm{Oi}|)}{\sum_{\mathrm{i}=1}^{\mathrm{N}} \mathrm{Ei}}\right) 100 \\
\mathrm{EMA}=\sum_{\mathrm{i}=1}^{\mathrm{N}} \frac{(|\mathrm{Ei}-\mathrm{Oi}|)}{\mathrm{n}} \\
\mathrm{CVQ}=\frac{\sigma}{\overline{\mathrm{Q}}} \\
\mathrm{CUC}=100\left[1-\frac{\sum_{\mathrm{I}}^{\mathrm{N}}|\mathrm{qi}-\overline{\mathrm{Q}}|}{\mathrm{nQ}}\right] \\
\mathrm{UE}=100\left[1-\frac{\sigma}{\overline{\mathrm{Q}}}\right] \\
\mathrm{GE}=100\left(1-\frac{\mathrm{Q}}{\mathrm{Q}_{1}}\right)
\end{gathered}
$$

em que:

Is - índice de erro da vazão, \% 
EMA - erro médio absoluto da vazão, $\mathrm{L} \mathrm{h}^{-1}$

CVQ - coeficiente de variação de vazão, \%

CUC - coeficiente de uniformidade de Christiansen, \%

UE - coeficiente de uniformidade de emissão da água, \%

GE - grau de entupimento dos emissores, \%

$\mathrm{E}_{\mathrm{i}} \mathrm{eO}_{\mathrm{i}}$ - enésimos valores de vazão estimados (vazão de projeto) e observados, respectivamente, no período de análise, $\mathrm{L} \mathrm{h}^{-1}$

n - número de emissores

$\sigma$ - desvio padrão das vazões, $\mathrm{L} \mathrm{h}^{-1}$

qi - vazão de cada emissor $\mathrm{i}, \mathrm{L} \mathrm{h}^{-1}$

Q - vazão média de todos os emissores, $\mathrm{L} \mathrm{h}^{-1}$

$\mathrm{Q}_{1}$ e $\mathrm{Q}_{2}$ - vazões obtidas nos microtubos nos primeiro e segundo períodos de teste, respectivamente, $\mathrm{L} \mathrm{h}^{-1}$

A determinação da uniformidade de emissão de água baseouse na metodologia apresentada por Merriam \&Keller (1978) e consistiu na coleta de dados em oito emissores, em quatro laterais; portanto, em cada uma das laterais foram selecionados emissores espaçados da seguinte maneira: primeiro, a 1/7, 2/7, 3/7, 4/7, 5/7, 6/7 e último. Com os dados de vazão em cada ponto de coleta determinou-se a vazão média dos emissores localizados na mesma distância, nas quatro laterais, para os períodos de 60 e 160 dias após instalação; em seguida, realizouse uma análise comparativa da vazão média com a vazão de projeto.

A altura e o diâmetro do caule das plantas fertigadas pelo sistema com microtubos (experimental) e mangueira (sistema testemunha) foram mensurados no final do ciclo das mudas de laranja, cujas avaliações foram realizadas com base na análise comparativa de médias aritméticas de todas as plantas; nos desvios padrão das amostras; coeficientes de variação; valores mínimos; valores máximos e as diferenças máximas entre as medições realizadas, possibilitando a comparação entre os métodos de fertigação utilizados.

O sistema padrão de irrigação adotado pela empresa é por mangueiras (sistema testemunha), de aplicação manual, constatando-se grande desperdício de água no momento de irrigar. Em função disto realizaram-se medições para quantificar a solução aplicada por planta, utilizando-se o sistema de fertigação com mangueiras e com microtubos. Para tanto foi medido, com o auxílio de uma proveta, o volume total da solução aplicada e drenada, por meio de ambos os métodos de fertigação, para posterior comparação entre os mesmos.

\section{RESULTADOS E DISCUSSÃO}

Pode-se observar, na Figura 3, uma análise comparativa da vazão de projeto (estimada) e as vazões médias das quatro laterais em cada posição, apresentadas do primeiro $(\mathrm{P})$ ao último microtubo (U), nos períodos de estudo correspondentes a $60 \mathrm{e}$ 160 dias após implantação do sistema de fertigação.

Os dados de vazão obtidos nos dois períodos de estudo variaram entre a vazão de projeto $\left(8,60 \mathrm{Lh}^{-1}\right)$ e $8,80 \mathrm{Lh}^{-1}$. O maior valor foi de $8,78 \mathrm{Lh}^{-1}$, obtido no período de 60 dias, acima, portanto, da vazão de projeto, possivelmente por ter ocorrido em função de pequenas diferenças no comprimento dos microtubos estando, sem dúvida, um pouco menor do que o

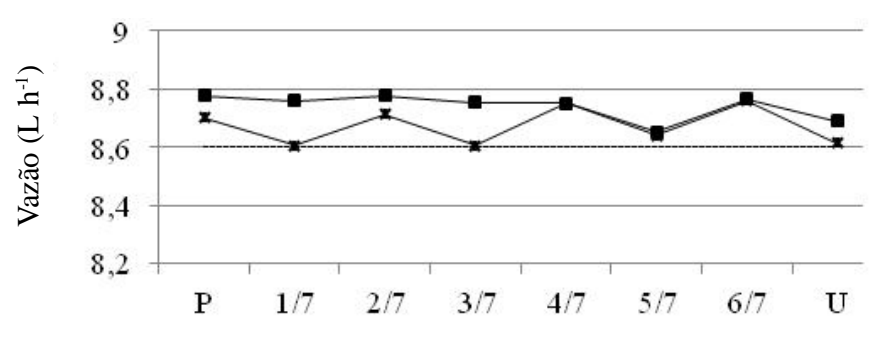

Fração da distãncia de coleta a o longo das linhas laterais

$\longrightarrow-160$ dias $\longrightarrow-60$ dias Fstimada Figura 3. Análise comparativa da vazão de projeto (estimada) e os valores médios obti dos nas quatro laterais, nas posições do primeiro (P) ao último (U ) microtubo, nos perío dos de 60 e 160 dias após implantação

comprimento necessário, seja por imperfeição no momento do corte ou na determinação pelo modelo matemático. Esta variação, porém, não apresenta interferência negativa para as plantas mas se nota que os valores de vazão média no período de 160 dias apresentaram pequena redução em alguns pontos de coleta ao longo das laterais, comparados com os das vazões obtidas aos 60 dias, ocorrendo uma redução de $0,16 \mathrm{Lh}^{-1}$ na posição 1/7. A distribuição das vazões médias foi boa, com uma faixa máxima de variação nos pontos de coleta de 0,12 e $0,15 \mathrm{Lh}^{-1}$ nos períodos de 60 e 160 dias, respectivamente porém, para uma afirmativa mais concreta será realizada análise da uniformidade de emissão.

$\mathrm{Na}$ Tabela 3 estão os resultados da análise estatística das vazões medidas nos microtubos, nos períodos de 60 e 160 dias após implantação do sistema de fertigação.

Tabela 3. Resultados estatísticos das vazões coletadas nos microtubos no final dos dois períodos de análise

\begin{tabular}{lcc}
\hline Variável analisada & $\begin{array}{c}\text { Período de 60 dias } \\
\text { após implantação }\end{array}$ & $\begin{array}{c}\text { Período de 160 dias } \\
\text { após implantação }\end{array}$ \\
Qest $\left(\mathrm{L} \mathrm{h}^{-1}\right)$ & 8,60 & 8,60 \\
Qmin $\left(\mathrm{L} \mathrm{h}^{-1}\right)$ & 8,40 & 8,37 \\
Qmax $\left(\mathrm{L} \mathrm{h}^{-1}\right)$ & 8,92 & 8,72 \\
Qméd $\left(\mathrm{L} \mathrm{h}^{-1}\right)$ & 8,70 & 8,67 \\
Qmod $\left(\mathrm{L} \mathrm{h} \mathrm{h}^{-1}\right)$ & 8,80 & 8,64 \\
EMA $\left(\mathrm{L} \mathrm{h}^{-1}\right)$ & 0,17 & 0,16 \\
UE $(\%)$ & 98,29 & 98,21 \\
CVQ $(\%)$ & 2,11 & 1,94 \\
IS $(\%)$ & 1,99 & 1,82 \\
GE $($ adm. & - & 0,50 \\
CUC $(\%)$ & 99,95 & 99,95 \\
\hline
\end{tabular}

Qest: vazão estimada; Qmin: vazão mínima; Omáx: vazão máxima; Qmed: vazão média; UE: coeficiente de uniformidade de emissão; EMA: erro médio absoluto: Is: índice médio de erro da vazão; CUC: coeficiente de uniformidade de Christiansen; GE: grau de entupimento dos microtubos

Pela Tabela 3 constata-se que a vazão coletada apresentou valor médio próximo ao da estimada, em ambos os períodos de teste e valores mínimos e máximos acima da vazão de projeto. Os dados de EMA, CVQ e Is foram baixos nos dois períodos de análise mostrando que o dimensionamento foi bom e que o sistema de fertigação nas condições desta pesquisa não apresentou entupimento, fato confirmado pelo GE baixo $(0,50)$. De acordo com Solomon (1979), coeficientes de variação de 
fabricação com valor de 0 a $3 \%$ podem ser classificados como excelente; portanto, como o coeficiente de variação de vazão segue a mesma metodologia do coeficiente de variação de fabricação, o mesmo se enquadra em tal classificação uma vez que apresentou valores de 2,11 e 1,94\%, respectivamente, aos períodos de 60 e 160 dias após instalação do experimento. As uniformidades de emissão obtidas nos dois períodos de análise foram de 98,29 e 98,21\%. De acordo com Bralts (1986), parcela com irrigação localizada que apresenta UE acima de $90 \%$ é considerada excelente; logo, os valores obtidos se enquadram dentro desta classificação mantendo-se tais resultados próximos aos que se conseguem com gotejadores autocompensantes, com a vantagem de serem baratos e não terem apresentado entupimento. De acordo Mantovani \& Ramos (1994) os valores de CUC na irrigação por gotejamento devem estar compreendidos numa faixa superior a $90 \%$; portanto, o valor de $99,95 \%$ é excelente.

Além dessas análises realizou-se também uma avaliação do desperdício de solução utilizando-se o método de irrigação convencional com mangueiras, verificando-se que a quantidade de água aplicada semanalmente pelo sistema com mangueiras adotado pela empresa foi de 1,20 L por planta, tendo-se coletado, em média, 0,50 L de volume drenado. A vazão média aplicada com microtubos foi de $8,67 \mathrm{Lh}^{-1}$, sendo que o sistema funcionava durante 7,0 minutos em duas irrigações durante a semana; desta forma, o volume médio aplicado foi de 1,01 L de solução por planta e o volume drenado foi, em média, de 0,20 L. Comparando os dois métodos nas condições de manejo adotadas e se utilizando o sistema com microtubo, aumenta-se a água retida no sistema radicular, reduzse o desperdício de água e nutrientes por drenagem em $0,30 \mathrm{~L}$ aplicados por planta semanalmente e em consequência, minoram os custos para a empresa e a poluição do meio ambiente.

$\mathrm{Na}$ Tabela 4 se apresentam os resultados estatísticos de média, desvio padrão (ó), coeficiente de variação (CV), mínimo, máximo e diferença máxima dos valores obtidos para diâmetro do caule e altura das plantas cultivadas na bancada experimental (manejadas com microtubo) e na bancada testemunha (manejadas com mangueira) utilizando-se o procedimento padrão de irrigação adotado pela empresa.

Tabela 4. Resultados de média, desvio padrão $(\sigma)$, coeficiente de variação (CV), mínimo, máximo e diferença máxima, obtidos para os dados de diâmetro do caule e altura das plantas irrigadas com microtubo e mangueira

\begin{tabular}{|c|c|c|c|c|}
\hline \multirow{2}{*}{$\begin{array}{c}\text { Parâmetros } \\
\text { analisados }\end{array}$} & \multicolumn{2}{|c|}{ Diâmetros do caule (mm) } & \multicolumn{2}{|c|}{ Alturas das plantas (mm) } \\
\hline & Experimental & Testemunha & Experimental & Testemunha \\
\hline Média & 7,43 & 7,35 & 457,79 & 462,08 \\
\hline$\sigma$ & 0,66 & 0,56 & 53,01 & 43,01 \\
\hline CV (\%) & 8,94 & 7,59 & 11,58 & 9,31 \\
\hline Mínimo & 6,21 & 6,29 & 340,00 & 375,00 \\
\hline Máximo & 8,28 & 8,28 & 510,00 & 510,00 \\
\hline $\begin{array}{l}\text { Diferença } \\
\text { máxima }\end{array}$ & \multicolumn{2}{|c|}{0,64} & \multicolumn{2}{|c|}{18,88} \\
\hline
\end{tabular}

Analisando os resultados apresentados na Tabela 4, observase que os dados médios de diâmetro basal do caule igual a 7,43 e 7,35 mm utilizando-se a bancada experimental com microtubos e a bancada testemunha, respectivamente, são próximos, o mesmo ocorrendo para a altura média atingida pelas mudas de laranja com valores de 457,79 e 462,08 mm. Em ambos os métodos de manejo utilizados as plantas apresentaram tanto diâmetros quanto alturas desuniformes; entretanto, os dados de coeficientes de variação foram baixos.

Comparando os resultados apresentados pelos dois métodos de fertigação utilizados, notam-se pequenas diferenças, tanto para os dados de diâmetro do caule quanto para os de altura atingida pelas plantas, no que se refere aos valores mínimos e máximos analisados. A maior diferença de diâmetro do caule foi de $0,64 \mathrm{~mm}$ e para a altura das plantas foi de 18,88 mm. Essas análises evidenciam que o sistema de fertigação com microtubo foi mais eficiente tendo em vista que o volume de solução aplicado foi menor; além disso, os valores de diferenças máximas apresentados tanto nos diâmetros quando nas alturas, podem ser considerados baixos, sendo aceitáveis para comercialização.

Apesar de ter ocorrido maior retenção de água no substrato utilizando-se microtubo, conforme comentado antes, observouse que este fato não interferiu nos valores de diâmetro do caule nem na altura das plantas; provavelmente possa ter ocorrido em função de terem sido supridas as necessidades hídricas e minerais das plantas, em ambas as condições, com microtubos e mangueiras, possibilitando que as plantas não apresentassem diferenças no desenvolvimento.

\section{CONCLUSÕES}

1. Nos períodos de estudo de 60 e 160 dias após implantação, as vazões médias dos emissores ao longo das linhas laterais se mantiveram praticamente constantes com uniformidade comparável à dos emissores autocompensantes.

2. O regime de escoamento turbulento foi viável tecnicamente para utilização de microtubo em sistema de fertigação, uma vez que os emissores não apresentaram problemas de entupimento no período avaliado.

3. As plantas fertigadas com microtubos não apresentaram diferença das plantas fertigadas no sistema tradicional com mangueiras, no que se refere ao diâmetro do caule e à altura.

4. O uso dos microtubos comparados ao sistema tradicional de irrigação com mangueiras, mostrou-se vantajoso em razão de possibilitar redução nos custos com mão-de-obra, água e fertilizantes.

5. A redução no volume de $0,30 \mathrm{~L}$ de solução (água e fertilizante) por planta, aplicada semanalmente através de microtubos, constitui um forte apelo para seu uso, tendo em vista os benefícios econômicos e ambientais que poderá gerar.

\section{Agradecimentos}

Os autores agradecem ao Ministério da Ciência e Tecnologia (MCT); ao Conselho Nacional de Desenvolvimento Científico e Tecnológico (CNPq) e à Fundação de Amparo à Pesquisa do Estado de São Paulo (FAPESP), pelo apoio financeiro a esta 
pesquisa, através do Instituto Nacional de Ciência e Tecnologia em Engenharia da Irrigação (INCTEI).

\section{LITERATURA CITADA}

Bhatnagar, P. R.; Srivastava, R. C. Gravity-fed drip irrigation system for hilly terraces of the northwest Himalayas. Bhaubaneswar, Irrigation Science, v.21, p.151-157, 2003.

Bralts, V. F.; Kesner, C. D. Drip irrigation field uniformity estimation. American Society of Agricultural Engineers, v.26, p.1369-1374, 1986.

Dias, N. da S.; Duarte, S. N.; Gheyi, H. R.; Medeiros, J. F. de; Soares, T. M. Manejo da fertirrigação e controle da salinidade do solo sob ambiente protegido, utilizando-se extratores de solução do solo. Revista Brasileira de Engenharia Agrícola e Ambiental, v.9, p.496-504, 2005.

Donagemma, G. K.; Ruiz, H. A.; Alvarez, V. H.; Ferreira, P. A.; Cantarutti, R. B.; Silva, A. T.; Figueiredo, G. C. Índice de uniformidade de distribuição do amônio, nitrato, potássio e fósforo, em Latossolos sob condições de fertigação. Revista Brasileira de Engenharia Agrícola e Ambiental, v.14, p.575$581,2010$.

Duenhas, L. H.; Bôas, R. L. V.; Souza, C. M. P.; Oliveira, M. V. A. M.; Dalri, A. B. Produção, qualidade dos frutos e estado nutricional da laranja Valência sob fertirrigação e adubação convencional. Engenharia Agrícola, v.25, p.154-160, 2005.

Laurindo, V. T.; Silva, G. O.; Pavani, L. C.; Quaggio, J. A. Padrão de distribuição de $\mathrm{K}^{+}, \mathrm{Ca}^{++}, \mathrm{Mg}^{++}$e $\mathrm{P}$ no solo de um pomar de citros em função da fertirrigação. Engenharia Agrícola, v.30, p.909-921, 2010.
Mantovani, E. C.; Ramos, M. M. Eficiência na aplicação da água. In: Costa, E. F.; Vieira, R. F.; Viana, P. A. Quimigação: Aplicação de produtos químicos e biológicos via irrigação. Brasília: Embrapa-SPI, 1994. p.135-152.

Merriam, J. L.; Keller, J. Farm irrigation system evaluation: a guide for management. Logan: Utah State University, 1978. 271p.

Soares, T. M. Utilização de águas salobas no cultivo da alface em sistema hidropônico NFT como alternativa agrícola condizente ao semi-árido brasileiro. Piracicaba: ESALQ, 2007. 268p. Tese Doutorado

Soares, T. M.; Duarte, S.N.; Graf, C. C. D.; Zanetti, M.; Zocchi, S. S. Produção de mudas cítricas utilizando águas salinas. Irriga, v.10, p.288-298, 2005.

Solomon, K. Manufacturing variation of trickle emitters irrigation equipment. American Society of Agricultural Engineers, v.22, p.1034-1038, 1979.

Souza, J. A. A. de; Cordeiro, E. de. A.; Costa, E. L. da. Aplicação de hipoclorito de sódio para recuperação de gotejadores entupidos em irrigação com água ferruginosa. Revista Brasileira de Engenharia Agrícola e Ambiental, v.10, p.5-9, 2006.

Souza, R. O. R. M.; Botrel, T. A. Modelagem para dimensionamento microtubo em irrigação localizada. Revista Brasileira de Engenharia Agrícola e Ambiental, v.8, p. 16-22, 2004.

Souza, W. J. Escoamento em regime turbulento aplicado à Irrigação localizada com microtubos. Piracicaba: ESALQ, 2008.117p. Dissertação Mestrado

Vale, D. W. do; Prado, R. de M.; Souza, H. A. de; Martins, A. B. G. Doses de nitrogênio, fósforo e potássio na nutrição do porta-enxerto cítrico de limoeiro 'Cravo'. Scientia Agrária, v.10, p.61-66, 2009. 